\title{
ANÁLISE DOS RISCOS ERGONÔMICOS DA ATIVIDADE DO GESSEIRO EM UM CANTEIRO DE OBRAS NA CIDADE DE JOÃO PESSOA/PB ATRAVÉS DO SOFTWARE WINOWAS
}

\section{ANALYSIS OF THE ERGONOMIC RISKS OF THE ACTIVITY OF THE PLASTERER IN A CONSTRUCTION SITE IN THE CITY OF JOÃO PESSOA/PB THROUGH THE SOFTWARE WINOWAS}

\author{
Sanzia Bezerra Ribeiro ${ }^{1}$;Maria Márcia Souto ${ }^{2}$;Ivan Cavalcante Araújo Júnior ${ }^{3}$ \\ ${ }^{1}$ Universidade Federal da Paraíba - Paraíba - Brasil - sanziar@uol.com.br \\ ${ }^{2}$ Universidade Federal da Paraíba - Paraíba - Brasil - masouto@producao.ct.ufpb.br \\ Universidade Federal da Paraíba - Paraíba - Brasil - ivanaraujojr@hotmail.com
}

Recebido para publicação em: 22/03/05

Aceito para publicação em: 10/05/05

\begin{abstract}
Resumo
O escopo deste estudo baseou-se na análise dos riscos ergonômicos da atividade do gesseiro em um canteiro de obras na cidade de João Pessoa, identificando as principais posturas adotas pelos mesmos ao longo da sua jornada laboral. A análise das posturas foi realizada através do software WinOWAS e a partir disso, pode-se caracterizar a atividade do gesseiro como um trabalho que exige do trabalhador, na maioria das operações, posturas inadequadas, com nível de esforço grande uma vez que realizam grande parte das atividades em inclinação lateral e flexão do tronco e manuseiam cargas de $40 \mathrm{~kg}$ (peso equivalente de cada saco de gesso) ao longo de sua jornada de trabalho, fatos esses que podem contribuir para o desenvolvimento de lesões músculo-esqueléticas nesses trabalhadores.
\end{abstract}

Palavras chave: Análise ergonômica; postura; construção civil; gesseiro; WinOWAS.

\section{Introdução}

Conforme Iida (1992), a construção civil é um ramo de atividade que emprega um grande contigente de mão-de-obra em todo o mundo, principalmente daquela semi-qualificada. Apesar de ser uma das mais antigas atividades produtivas do homem, ela ainda é pouco estudada. É uma atividade que possui tarefas árduas e complexas e o índice de acidentes desse setor é relativamente alto, devido a grande variedade de tarefas executas pelos trabalhadores, que apresentam pouca ou nenhum treinamento prévio para a realização das mesmas.

Outro problema que ocorre entre os trabalhadores da construção civil é o fato dos mesmos subestimarem os riscos existentes no ambiente de trabalho, fato esse que ocasiona uma necessidade de treinamento e conscientização quanto aos riscos existentes em cada situação de trabalho bem como a forma correta de prevenção de acidentes do trabalho.

As lesões músculos esqueléticas (LME), segundo Rebelo, (2002) são um conjunto de patologias cuja causa encontra-se relacionada com a exposição a fatores de riscos no local de trabalho de origem biomecânica e/ou psicosocial sendo uma expressão de uma solicitação 
exarcerbada das estruturas músculo-esqueléticas.

Pesquisas recentes demonstram que as disfunções da coluna vertebral apresentam uma alta incidência entre a população geral, ocupando o $2^{\circ}$ lugar na procura de assistência médica em decorrência de doenças crônicas e uma das principais causas das faltas no trabalho custando aos cofres públicos cifras elevadíssimas (LOESER, 1990 APUD KSAN, 2003).

$\mathrm{O}$ trabalhador que realiza suas atividades laborais em posturas inadequadas apresenta sensações desagradáveis e alterações no funcionamento do organismo decorrentes do aumento da fadiga. A sobrecarga estática causa agressões ao sistema locomotor, aumento da pressão intratorácica e abdominal, alterações circulatórias, e consequentemente fadiga muscular (SANTOS, 2002).

Segundo Cartaxo (1997), a ergonomia tem como objetivo a redução das doenças ocupacionais, fadiga muscular, situações de riscos e acidentes, proporcionando uma redução nas perdas, danos e custos à empresa e um melhor conforto, produtividade e desempenho do trabalhador.

Para tornar prática a análise da postura no trabalho facilitando sua identificação e registro, várias são as ferramentas existentes e dentre elas podemos citar alguns softwares, como o WinOWAS (Ovako Working Posture Analysin System) adequado para análise do corpo interiro em situações de trabalho dinâmico.

Iida, (1992) descreve que esse método (OWAS) foi desenvolvido na Finlândia, na década de 70, tendo como objetivo criar informações para melhorias dos métodos de trabalho pela identificação de posturas corporais inadequadas durante a realização da atividade. Esses pesquisadores encontraram 72 posturas típicas resultantes de diferentes combinações das posições do dorso (4 posições típicas), braços (3 posições típicas) e pernas (7 posições típicas).

Guimarães, (2002) informa que o método classifica o esforço físico em 4 categorias de acordo com as posturas adotadas no trabalho e a força exercida em uma ação específica:

Classe 1 - Postura normal, não é exigida nenhuma medida corretiva;

Classe 2 - Postura que deve ser verficada durante a próxima revisão rotineira dos métodos de trabalho; carga de trabalho levemente prejudicial;

Classe 3 - A carga física da postura é prejudicial, sendo necessárias medidas para mudar a postura o mais rápido possível;

Classe 4 - A carga física da postura é extremamente prejudicial, necessitando de medidas imediatas para mudar as posturas.

Conforme estudos realizado por Guimarães, 2002 em empresas da construção civil pesada, o método WinOWAS, a versão computadorizada do OWAS, tem se mostrado uma ferramenta valiosa na identificação de problemas em situações de trabalho com manuseio e transporte de carga.

Diante do exposto pretendemos com esse trabalho fazer uma análise dos riscos ergonômicos da atividade do gesseiro, em um canteiro de obras da cidade de João Pessoa/PB bem como, identificar, registrar e analisar as principais posturas adotadas pelos mesmos ao longo de sua jornada de trabalho.

Esse foi um estudo de natureza qualitativa e quantitativa, tipo de campo e descritiva onde as ferramentas utilizadas para elaboração da pesquisa foram dados coletados em entrevista informal com o dono da empresa e aplicação de um formulário semi-estruturado com cada trabalhador. $\mathrm{O}$ trabalho foi filmado e fotografado sendo esse material utilizado para a análise postural do gesseiro, através da versão computadorizada do OWAS, o WinOWAS.

\section{Caracterização da atividade do gesseiro}

A atividade do gesseiro da micro empresa em estudo é composta basicamente por 12 etapas baseadas no manual do aplicador de gesso do SENAI/PE relacionadas a seguir:

- Preparação das mestras (réguas utilizadas para nivelamento das paredes a serem revestidas); 
- Colocação das mestras que definirá a espessura do revestimento em conformidade com o prumo e esquadro da parede;

- Execução do Capiaço (Colocação das réguas com a pasta de gesso sobre as quinas, janelas, vigas, etc)

- Preparação da argamassa (Carregamento de água, carregamento dos sacos de gesso, colocação da água e do gesso no caixote, mistura da massa manualmente);

- Retirada das mestras;

- Conferência dos panos de parede se correspondem a largura das mestras;

- Aplicação da Argamassa (Pasta de gesso);

- Retirada do excesso da argamassa;

- Sarrafeamento (utilizando régua metálica apoiada sobre as mestras em movimentos de vaivém, "cortando" a superfície da argamassa até que seja atingido o nível das mestras).

- Acabamento Fino

- Aplicação da argamassa acima de 2,0m com sarrafeamento;

- Limpeza dos instrumentos (espátulas, caixotes, réguas, etc) para preparação de um novo ciclo de atividades.

\section{Apresentação dos resultados da pesquisa}

A pesquisa foi realizada em uma microempresa com 27 funcionários (1 diretor administrativo e 1 operacional, 21 gesseiros e 4 ajudantes) localizada na cidade de João Pessoa/Pb que terceriza serviços de revestimento interno em gesso. Dentre esses, foi selecionada uma amostra composta por 6 gesseiros e 2 ajudantes, com média de idade de 23,8 anos.

Em relação ao grau de instrução $25 \%$ têm o curso fundamental incompleto ( 2 operários), $12,5 \%$ o $1^{\circ}$ grau incompleto ( 1 operário), $25 \%$ o $1^{\circ}$ grau completo, $12,5 \%$ o $2^{\circ}$ grau incompleto e $25 \%$ o $2^{\circ}$ grau completo. Em termos de tempo de serviço, $62,5 \%$ (5 operários) estão a menos de um ano trabalhando como gesseiro, $12,5 \%$ entre 1 a 5 anos de tempo de serviço e $25 \%$ acima de 5 anos.

Quanto ao dia da semana que sentem menos disposição para o trabalho, a maioria dos trabalhadores sentem-se menos dispostos na segunda e minoria na sexta. Os mesmos justificaram essa indisposição pelo fato do corpo "descansar" no fim de semana e na segunda - feira ainda não se encontrarem completamente recuperados para realizar o pesado.

Figura 1 - Dias da semana que os gesseiros apresentam menos disposição para trabalhar.

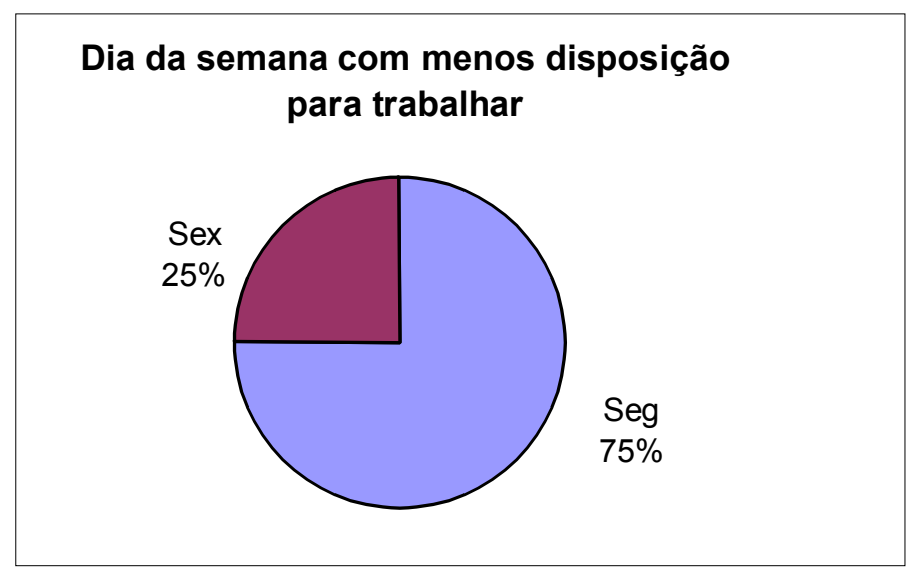

Fonte: Pesquisa de campo

Em relação a hora do dia que sentem menos disposição, $75 \%$ respondeu que no final do expediente, entre 15:00 -17:00hs o desempenho cai enquanto que 25\% respondeu ser depois do almoço, entre 12:00-14:00hs, que isso acontece.

No que se diz respeito a fadiga física, os gesseiros apenas sentem cansaço no final da jornada de trabalho, sendo que alguns não sentem cansaço. Esse dado corrobora com o dado 
anterior de que a atividade do gesseiro gera um aumento da fadiga física principlamente no final do expediente representada pela queda do rendimento.

Figura 2 - Período da jornada de trabalho que os gesseiros sentem fadiga física.

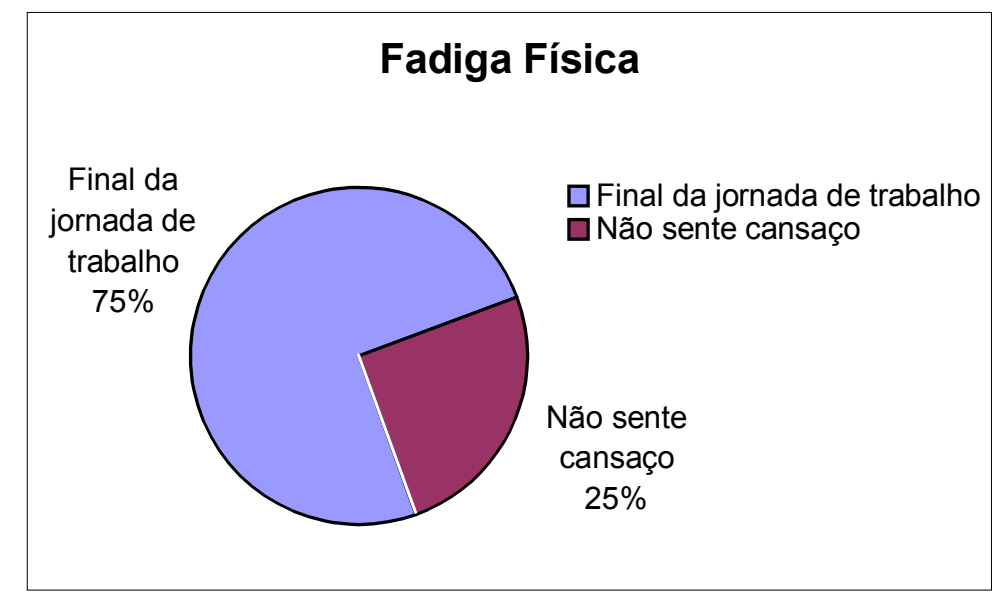

Fonte: Pesquisa de campo

No tocante a sentir dor em alguma região do corpo, 25\% respondeu que sempre sente, $37,5 \%$ respondeu que ás vezes sente algum tipo de dor, 25\% respondeu que raramente e $12,5 \%$ respondeu que não sente dor. Quanto a localização da dor, 40\% respondeu ser na região lombar, 30\% nos membros inferiores, $15 \%$ na coluna torácica e $15 \%$ nos membros superiores.

Figura 3 - Localização corporal da dor.

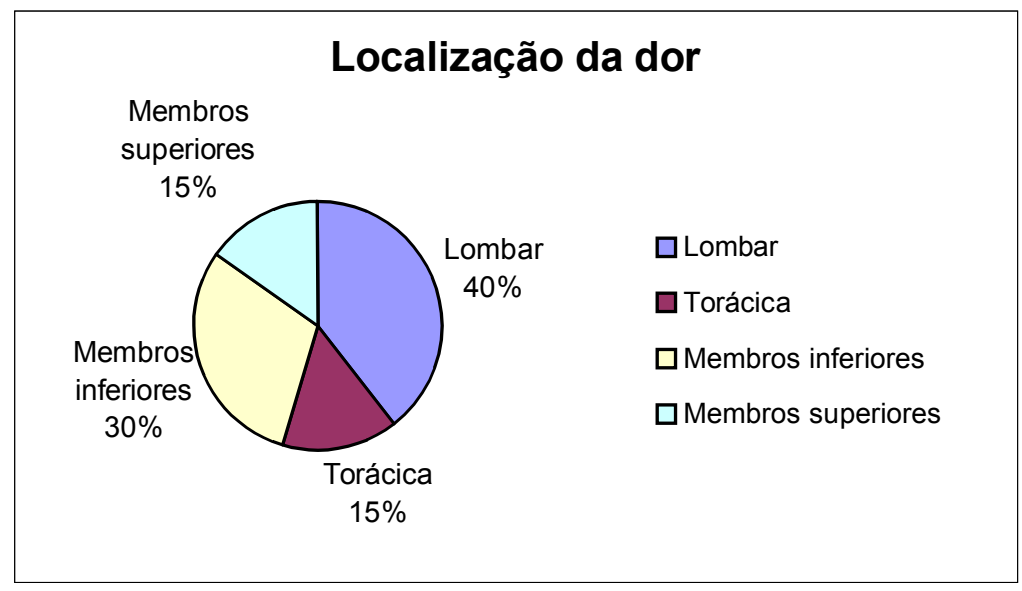

Fonte: Pesquisa de campo

Ao classificarem a dor, $57,1 \%$ respondeu ser uma dor moderada e 42,8\% classificaram como fraca. A mesma porcentagem foi atribuída quando foi perguntado se a dor aumentava durante a realizar da atividade laboral e se já sentiam dor antes de iniciarem o ofício de gesseiro: $57,1 \%$ responderam que sim e $42,8 \%$ responderam que não.

Sobre questões de segurança, todos funcionários confirmaram o fornecimento de equipamentos de proteção individual (EPIs) por parte da empresa sendo esses botas, fardamento, capacetes e máscara e que os mesmos são considerados adequados por todos os funcionários e necessária a sua utilização. Porém, foi descrito pelos operários utlizarem sempre apenas a bota e o fardamento. Os outros equipamentos de proteção são utlizados ás vezes pelo fato dos operários não considerarem necessário utlizarem regularmente ou mesmo por considerar difícil trabalhar com o equipamento informando que o mesmo chega a atrapalhar o desenvolver de sua atividade laboral. Todos informaram não receberem nenhum treinamento sobre segurança, apenas o fornecimento dos 
EPIs.

\section{Análise postural}

O método de análise postural do software WinOWAS foi escolhido na aplicação deste trabalho, por se tratar de uma avaliação onde se detecta os constrangimentos posturais envolvidos na atividade profissional do gesseiro a qual este estudo se propôs, proporcionando uma rápida identificação da gravidade das posturas adquiridas durante as atividades de trabalho, sugerindo a urgência ou não das providências que devem ser tomadas de acordo com as categorias reveladas.

A partir dos dados introduzidos, codificações da postura de acordo com o Quadro 1, são apresentados os resultados de cada uma das posturas analisadas durante a jornada de trabalho do gesseiro por categoria (Quadro 2) permitindo análise de adaptação para medidas corretivas a serem aplicadas.

Quadro 1 - Codificação da postura.

\begin{tabular}{|c|c|c|}
\hline \multirow{18}{*}{ 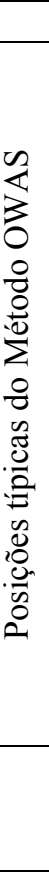 } & \multicolumn{2}{|r|}{ Codificação da Postura } \\
\hline & \multirow{4}{*}{$\begin{array}{c}1^{\circ} \text { Dígito } \\
\text { Costas }\end{array}$} & 1-Ereta \\
\hline & & 2-Inclinada \\
\hline & & 3-Ereta e torcida \\
\hline & & 4-Inclinada e torcida \\
\hline & \multirow{3}{*}{$\begin{array}{c}2^{\circ} \text { Dígito } \\
\text { Braços }\end{array}$} & 1-Braços abaixo dos ombros \\
\hline & & 2-Um braço no nível ou acima dos ombros \\
\hline & & 3-Ambos no nível ou acima dos ombros \\
\hline & \multirow{7}{*}{$\begin{array}{c}3^{\circ} \text { Dígito } \\
\text { Pernas }\end{array}$} & 1-Sentado \\
\hline & & 2-De pé com ambas as pernas esticadas \\
\hline & & $\begin{array}{l}\text { 3-De pé com o peso em uma das pernas } \\
\text { esticadas }\end{array}$ \\
\hline & & $\begin{array}{l}\text { 4-De pé ou agachado com os joelhos } \\
\text { dobrados }\end{array}$ \\
\hline & & $\begin{array}{l}\text { 5-De pé ou agachado com um dos joelhos } \\
\text { agachados }\end{array}$ \\
\hline & & 6-Ajoelhado em um ou ambos joelhos \\
\hline & & 7-Andando ou se movendo \\
\hline & \multirow{3}{*}{$\begin{array}{c}4^{\circ} \text { Dígito } \\
\text { Carga }\end{array}$} & 1-Força ou peso igual ou menor que $10 \mathrm{Kg}$ \\
\hline & & $2-10 \mathrm{Kg}<$ Força ou peso $<20 \mathrm{Kg}$ \\
\hline & & 3 -Força ou peso $>20 \mathrm{Kg}$ \\
\hline
\end{tabular}

Fonte: Adaptado de Freitas (2000)

Quadro 2 - Classificação das categorias.

\begin{tabular}{|l|l|}
\hline \multicolumn{2}{|c|}{ CATEGORIA } \\
\hline 1 & Não são necessárias medidas corretivas \\
\hline 2 & São necessárias correções futuras \\
\hline 3 & São necessárias correções logo que possível \\
\hline 4 & São necessárias correções imediatas \\
\hline \multicolumn{2}{|c|}{ Fonte: Adaptado de Freitas (2000) } \\
\hline
\end{tabular}

Diante dos resultados obtidos, Figura 4, nota-se que para a atividade do gesseiro as demandas das costas ao longo de toda a jornada de trabalho enquadram-se na categoria 2 , havendo necessidades de correções futuras. No que se diz respeito aos braços, os mesmo estão enquadrados na categoria 1, onde correções futuras não são necessárias. Em relação às pernas, o gesseiro enquadra-se na categoria 2 , onde correrções futuras são necessárias. 
Figura 4 - Resultado da análise postural do gesseiro durante sua jornada de trabalho através do software WinOWAS

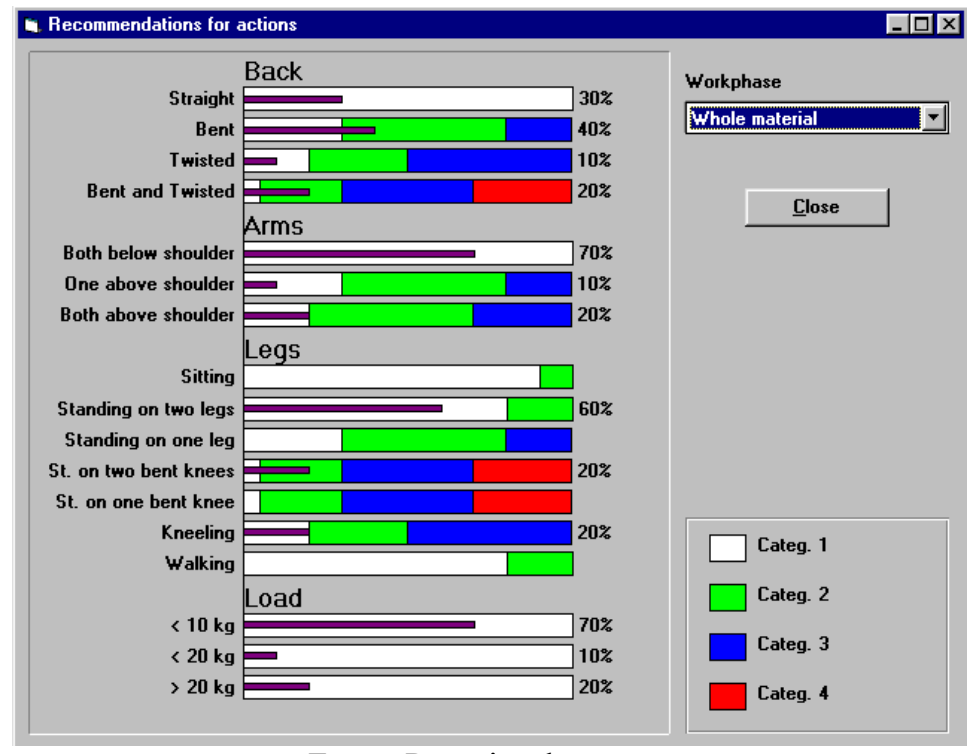

Fonte: Pesquisa de campo

No que se diz a respeito da classificação de cada uma das atividades do gesseiro, Figura 5, de acordo categorias propostas pelo Quadro 2 apresentado anteriormente, 20\% estão enquadradas na categoria 4, colocação das mestras e limpeza dos materiais, necessitando de correções imediatas e logo que possível. Outros $20 \%$ das atividades do gesseiro estão inclusas na categoria 3 , carregamento do balde com água e a retirada do gesso do saco, onde correções são necessárias logo que possível. Em relação a categoria 2, estão compreendidas 30\% das atividades; mistura do gesso, colocalção da massa de gesso na régua e a aplicação na parede; não havendo uma grande necessidade de correção postural. Finalmente, para a categoria 1, os outros $30 \%$ restantes das atividades; carregamento do cimento, retirada das mestras e aplicação na parede 2; pertencem a esta categoria, não sendo necessária nenhuma medida corretiva.

Figura 5 - Classificação das atividades do gesseiro

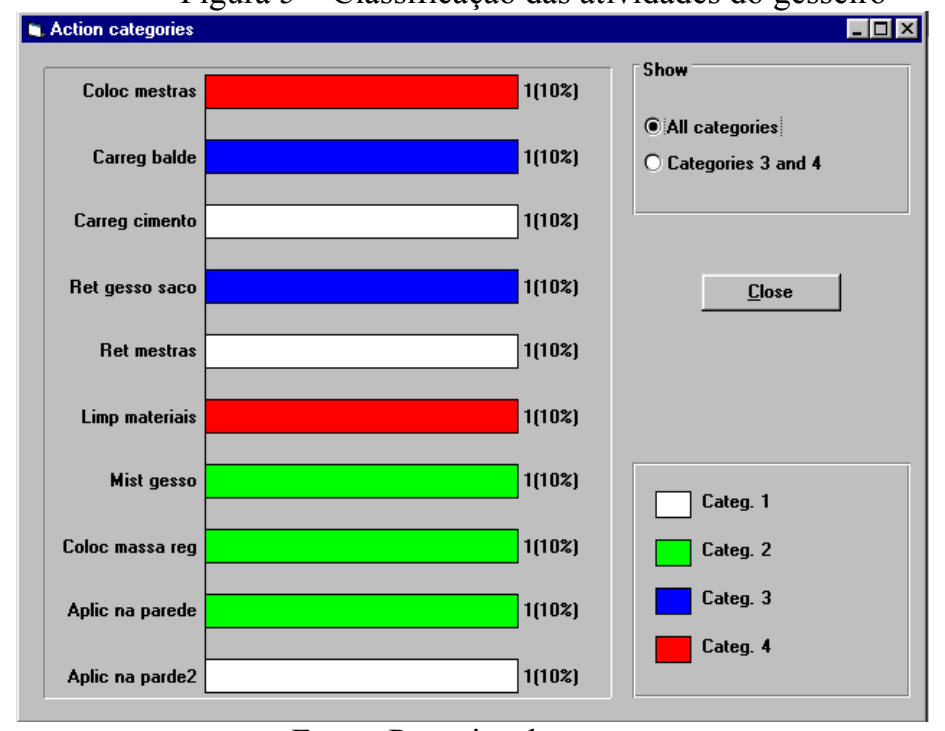

Fonte: Pesquisa de campo

\section{Conclusões}


Conforme Damlud et al(1986) apud Iida ,1992 ao realizar um trabalho de levantamento de carga de trabalho na construção civil, eles identificaram seis tipos de movimentos corporais executados por esses trabalhadores e definiu para cada movimento três níveis de esforço:

- Pequeno: quando, por exemplo, o trabalhador realizava a atividade em uma postura inclinada durante 10 a 30 s ou carregando peso de 1 a $4 \mathrm{~kg}$;

- Médio: postura inclinada durante 30 a 120 s ou carregamento peso de 5 a $19 \mathrm{~kg}$;

- Grande: postura inclinada durante mais de $120 \mathrm{~s}$ ou carregamento de peso de $20 \mathrm{~kg}$ ou mais.

Confirmando essa consideração nosso estudo demonstrou que a atividade do gesseiro é uma das inúmeras atividades desenvolvidas no ramo da construção civil, e como tal, exige grande esforço físico dos trabalhadores expondo os mesmos a vários riscos ocupacionais, dentre eles, os riscos ergonômicos. Esses riscos podem contribuir para o desenvolvimento de lesões músculoesqueléticas nesses trabalhadores.

Embora apresentando limitações, o método do software WinOWAS tem demonstrado benefícios no monitoramento de tarefas que impõe constrangimentos possibilitando identificar as posturas adotadas nas atividades mais prejudiciais e ao mesmo tempo indicar as regiões anatômicas mais atingidas.

A partir disso, podemos caracterizar a atividade do gesseiro como um trabalho que exige do trabalhador, na maioria das operações, posturas inadequadas, principalmente em em inclinação lateral e flexão do tronco, com nível de esforço grande, manuseiando cargas de $40 \mathrm{~kg}$ (peso equivalente de cada saco de gesso), várias vezes ao longo de sua jornada laborativa.

Tal aspecto não condiz com o que rege a lei trabalhista, bem como a NR17 (norma regulamentadora específica da Ergonomia) de que não deverá ser exigido, nem admitido o transporte manual de cargas, por um trabalhador cujo o peso seja suscetivel de compromoter sua saúde ou sua segurança e ainda, que todo trabalhador designado para o transporte manual regular de cargas, que não as leves, deve receber treinamento e instruções satisfatórias quanto aos métodos de trabalho que deverá utilizar com vistas a salvaguardar sua saúde e prevenir acidentes (NR17, 17.2.2 e 17.2.3).

Os resultados desse estudo, alertam para a necessidade de se intervir no método de trabalho orientando e treinando esses trabalhadores de como melhor realizar suas atividades através da minimização da exposição aos riscos ergonômicos que os mesmos encontram-se submetidos.

\begin{abstract}
The aim of this study was based on the, identifying the main postures adopted for the same ones along its day labor. The analysis of the postures was accomplished and starting from that, the activity of the plasterer can be characterized as a work that demands from the worker, in most of the operations, inadequate postures, with a high level effort once they accomplish most part of the activities in lateral inclination and flexing of the trunk and handle loads of 40kg (weigh equivalent of each sack of plaster) along its work day, facts that can contribute to the development of muscleskeletal lesions in these workers.
\end{abstract}

Key-Words: ergonomic analysis, posture, civil construction, plasterer, WinOWAS.

\title{
Referências
}

CARTAXO, Cristiana. (1997) - Estudo ergonômico do posto de trabalho do armador de laje: uma avaliação quantitativa dos esforços físicos na coluna vertebral decorrentes da postura de trabalho. Dissertação (mestrado em engenharia de produção). CT/UFPB. 
FREITAS, José Celso de Araújo. (2000) - Tarefa de revestimento externo de edificações verticais: análise ergonômica das condições de trabalho. Florianópolis 2000. Dissertação de Mestrado em Engenharia de Produção. DEPS, UFSC.

GUIMARÃES, Lia Buarque de Macêdo. (2002) - Análise postural da carga de trabalho nas centrais de armação e carpintaria de um canteiro de obras. IN: XII Congresso Brasileiro de Ergonomia, ABERGO. Anais. Recife

IIDA, I. (1992) - Ergonomia - Projeto e produção. Edgard Blücher. Sâo Paulo

KSAM, Jorgson. (2003) - Lombalgia: quebra de paradigmas. Revista CIPA, Ano XXIV, 280, pp 26-36.

OWAS (Acessado em: 04/05/04) - Ovako Working Posture Analysing Sistem. Tempere University of Technology Tempere, Finland. Disponível em: www.turva.me.tut.fi/owas.

REBELO, R.; SANTOS, R; LOURENÇO, L.(2002) Estudo ergonômico na indústria automóvel: identificação e hierarquização dos factores de risco e elaboração de recomendações na linha de montagem da suspenção dianteira. IN: XII Congresso Brasileiro de Ergonomia, ABERGO. Anais. Recife

SANTOS, Heliodório Honorato dos. (2002) - Análise Ergonômica do trabalho dos borracheiros de João Pessoa: Relação entre o estresse postural e a exigência muscular na região lombar. Dissertação (mestrado em engenharia de produção). CT/UFPB.

SENAI/DR/PE (2003) - Manual do aplicador de gesso. Recife, DITEC/DET.

VIDAL, Mario César Rodríguez. (2002) - Legislação e normas em ergonomia in: Ergonomia na empresa. Editora Virtual Científica. $2^{\text {a }}$ edição. Rio de Janeiro 